\title{
Anaerobic degradation of dairy wastewater in intermittent UASB reactors: influence of effluent recirculation
}

\author{
A. Silva, C. Couras, I. Capela, L. Arroja, H. Nadais* \\ CESAM \& Environmental and Planning Department \\ University of Aveiro \\ 3810-193-Aveiro, Portugal \\ nadais@ua.pt
}

Received: February 15, 2021 Revised: March 8, 2021. Accepted: March 13, 2021. Published: March 29, 2021.

\begin{abstract}
This work studied the influence of effluent recirculation upon the kinetics of anaerobic degradation of dairy wastewater in intermittent UASB (Upflow Anaerobic Sludge Bed) reactors. Several laboratory-scale tests were performed with different organic loads in a UASB reactor inoculated with flocculent sludge from an industrial wastewater treatment plant. The data obtained were used for determination of specific substrate removal rates and specific methane production rates and adjusted to kinetic models. A high initial substrate removal was observed in all tests due to adsorption of organic matter onto the anaerobic biomass which was not accompanied by biological substrate degradation as measured by methane production. Initial methane production was about $45 \%$ of initial soluble and colloidal substrate removal rate. This discrepancy was observed mainly in the first day of all experiments and was attenuated in the second day. Effluent recirculation raised significantly the rate of removal of soluble and colloidal substrate and methane productivity as compared to literature results for batch assays without recirculation.
\end{abstract}

Keywords-UASB reactor; dairy wastewater; feedless period; effluent recirculation; kinetics

\section{INTRODUCTION (Heading 1)}

Presently Upflow Anaerobic Sludge Bed (UASB) reactors face significant challenges in what concerns their applicability for the treatment of complex lipid-rich wastewater of which dairy wastewater is an example. As an option to overcome operating problems verified in continuous systems studies have been developed on the intermittent operation of UASB reactors used for treating dairy wastewater [1, 2] or for treating proteinaceous wastewater [3], slaughterhouse wastewater [4], domestic wastewater [5] or olive mill wastewater [6]. The beneficial effects of discontinuous feeding of fatty substrates on anaerobic systems have also been confirmed by Palatsi et al. [7]. The intermittent operation is composed of a succession of feed and feedless periods where a feed period followed by a feedless period forms an intermittent cycle. During the feed periods high substrate removal rates are achieved which are not accompanied by the expected methane production, leading to heavy non degraded substrate accumulation onto the biological biomass that constitutes the UASB sludge bed. The feedless period is crucial for the degradation of the complex substrates (fats and long chain fatty acids - LCFA) that accumulate in the biomass during the feed period, mainly by adsorption mechanisms [1, $2,6]$. During the feed periods the intermittent UASB reactor works as a continuous reactor and during the feedless periods it works as a batch reactor. It has been shown that effluent recirculation during the feedless periods of intermittent operation are very beneficial for reactor performance especially in terms of methane production [8].

Insights on what happens during the feedless periods are important to understand the functioning of the intermittent UASB systems. Literature presents several results for the degradation of dairy wastewater in batch reactors. Yet if effluent recirculation is applied during the feedless periods the hydrodynamic conditions may significantly alter the COD (Chemical Oxygen Demand) removal mechanisms and subsequent biological degradation observed in feedless periods of intermittent systems. The importance of the hydrodynamic conditions is related to mass transfer mechanisms [9] and to adsorption phenomena responsible for the major percentage of initial COD removal from complex wastewaters in anaerobic systems $[10,11]$. In this framework this investigation aimed at evaluating the influence of effluent recirculation on the kinetics of dairy wastewater degradation in the feedless periods of intermittent UASB operation.

\section{MATERIALS AND METHODS}

In this work a lab-scale UASB reactor was used with a working volume of 6 litres topped with a gas-solid-liquid separator and operated at mesophilic temperature $\left(35 \pm 1^{\circ} \mathrm{C}\right)$ by means of a water jacket connected to a thermostatic bath. The UASB reactor is shown in Fig. 1. At the beginning of each test the reactor was seeded with approximately 4 litres of flocculent biomass adapted to dairy wastewater from an industrial wastewater treatment plant. 


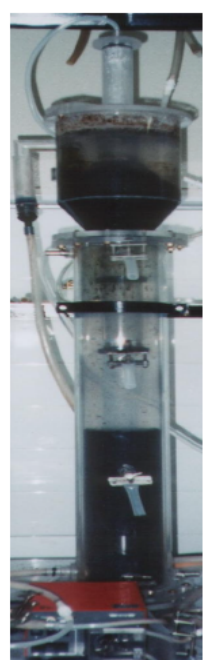

Fig. 1. Laboratory-scale UASB reactor used in this work.

The feed was prepared from dilution of semi-skimmed milk and supplementing with nutrients and alkalinity [1]. Table I presents the composition of the milk used for preparing the feed.

TABLE I. CHARACTERIZATION OF THE MILK USED FOR FEED

\begin{tabular}{|l|c|}
\hline Parameter $(\mathrm{g} / \mathrm{L})$ & Value \\
\hline Proteins & 32 \\
Carbon hydrates & 48 \\
Total lipids & 16 \\
Saturated lipids & 10 \\
Calcium & 1.2 \\
COD & 147.47 \\
\hline
\end{tabular}

$\mathrm{COD}=$ Chemical Oxygen Demand.

The reactor was operated in a discontinuous mode where the feed was pumped into the reactor and then the produced effluent was recirculated, without any extra feeding, at volumetric flow of $0.5 \mathrm{~L} / \mathrm{h}$. Table II presents the experimental conditions for the five tests performed in this work.

TABLE II. EXPERIMENTAL SET-UP

\begin{tabular}{|c|c|c|}
\hline Test & $\begin{array}{c}\text { Organic load } \\
\text { (g COD/L) }\end{array}$ & $\begin{array}{c}\text { Biomass } \\
(\mathrm{gVSS} / \mathrm{L})\end{array}$ \\
\hline 1 & 0.333 & 4.763 \\
2 & 0.666 & 4.763 \\
3 & 4.460 & 4.456 \\
4 & 8.910 & 5.127 \\
5 & 17.270 & 4.317 \\
\hline
\end{tabular}

After recirculation started the monitoring plan was implemented consisting of daily analysis of total COD, paper filtered COD (CODpf), membrane filtered COD (CODmf), total and volatile suspended solids (TSS and VSS), $\mathrm{pH}$ and volatile fatty acids (VFA). Paper filtered COD samples
(CODpf) were prepared using paper filters with a pore diameter of 1,2 $\mu \mathrm{m}$ (Whatman Inc. Reeve Angel, grade 403, 4,7 cm). Membrane filtered COD samples (CODmf) were prepared with membrane filters with a pore diameter of 0,45 $\mu \mathrm{m}$ (Schleicher \& Schuel Purabind, Ø 4,7 cm). Membrane filtered COD represents the soluble COD fraction whilst the paper filtered COD represents the soluble and colloidal COD fraction [4].

The produced biogas was measured by a water displacement system. Methane content in biogas was monitored using a gas chromatograph Shimadzu GC - 9a, equipped with a Supleco Molcular Sieve 5 A column and a Thermal Conductivity Detector $\left(\mathrm{T}=100^{\circ} \mathrm{C}\right)$. Injection temperature was $45^{\circ} \mathrm{C}$ and Helium was used as carrier gas $\left(\mathrm{P}=4.4 \mathrm{~kg} / \mathrm{cm}^{2}\right)$. Volatile fatty acids determination was carried out in a gas chromatograph Chrompack CP 9001 equipped with a Chrompack CP - sil5 - CB column and a Flame Ionization Detector $\left(\mathrm{T}=300^{\circ} \mathrm{C}\right)$. The injection temperature was $270^{\circ} \mathrm{C}$ and Helium was used as carrier gas with a volumetric flow of 8 $\mathrm{ml} / \mathrm{min}$

\section{RESULTS AND DISCUSSION}

The profiles of CODpf, cumulative methane production, removal of CODpf and methanization of removed CODpf were obtained for all the tests performed. Figs. 2 to 5 present results for the two higher loads tested $(8.91 \mathrm{~g} / \mathrm{L}$ and $17.27 \mathrm{~g}$ $\mathrm{COD} / \mathrm{L})$.

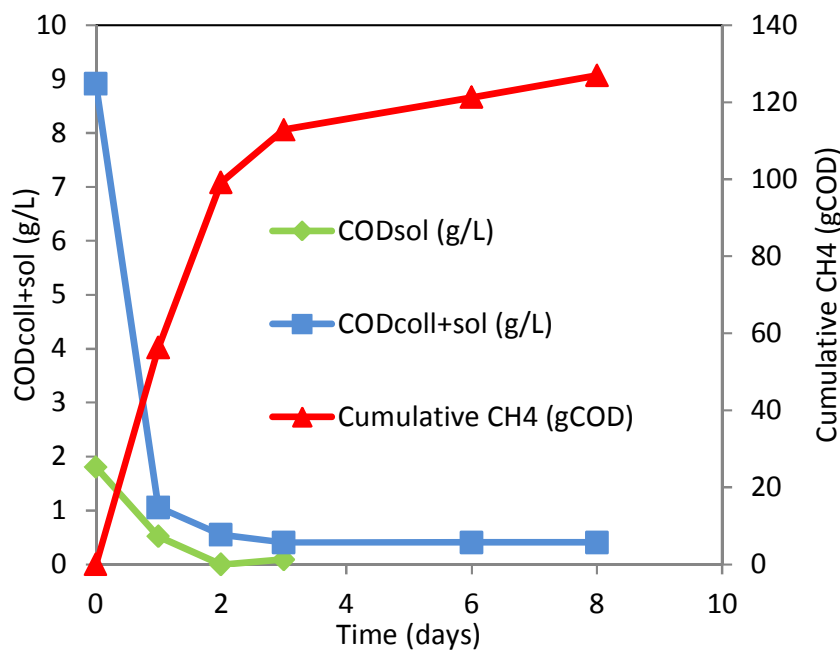

Fig. 2. $\mathrm{COD}$ and $\mathrm{CH}_{4}$ profile for test $4(8.91 \mathrm{~g} \mathrm{COD} / \mathrm{L})$. 


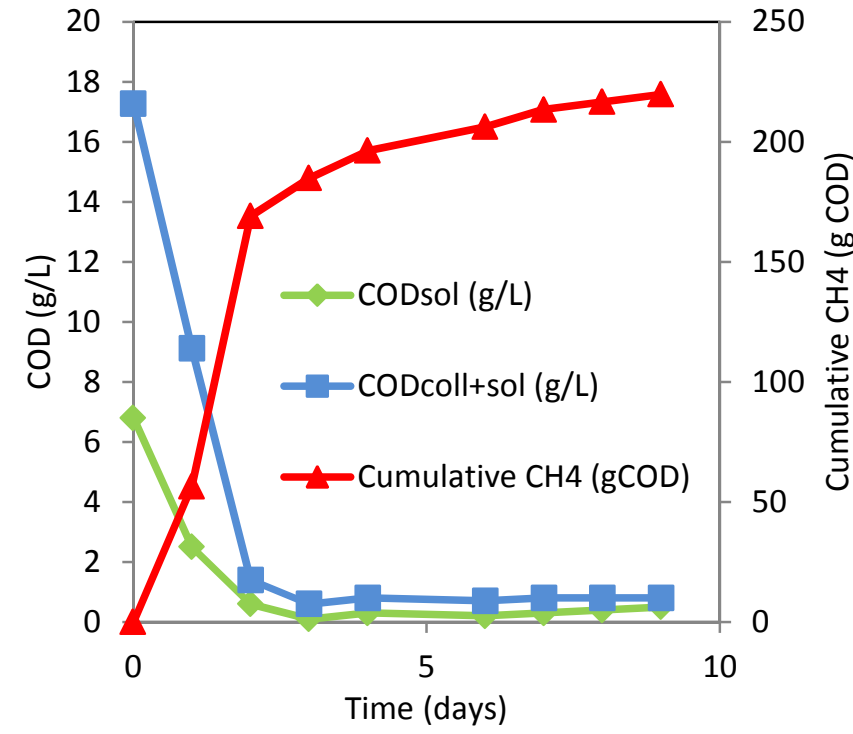

Fig. 3. $\mathrm{COD}$ and $\mathrm{CH}_{4}$ profile for test $5(17.27 \mathrm{~g} \mathrm{COD} / \mathrm{L})$.

For all the organic loads tested a significant decrease in CODpf was observed during the first day of the tests with $75 \%$ - 90\% CODpf removal for all the tests except the higher load (only 43\% CODpf removal in the first day). From the second day onwards the CODpf values are approximately constant in time except for the test with the higher load (17.27 g COD/L.d) in which an important decrease of CODpf was observed in the second day (Fig. 3). The values of volumetric methane production present a tendency towards stabilization only from the third day onwards for all the tests except for the lower load (0.33 g COD/L.d, data not shown). With this lower load the tendency to diminish the methane production was observed only from the fifth day of the test (data not shown).

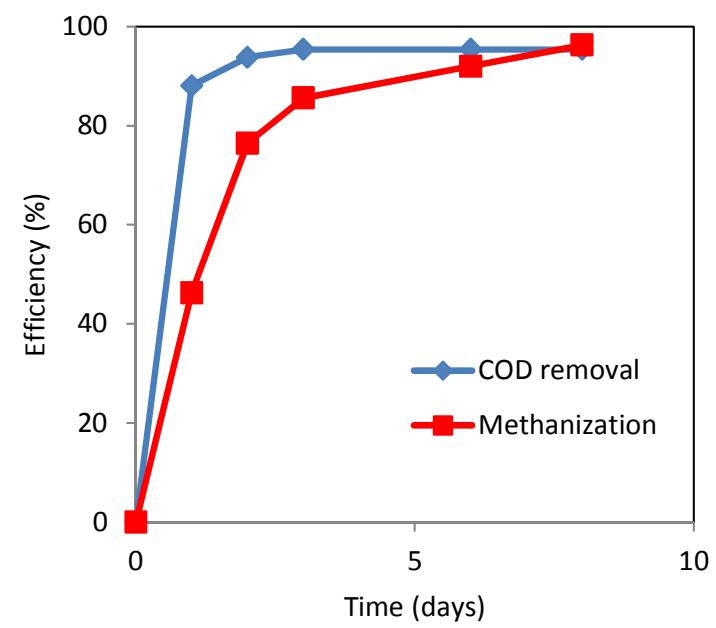

Fig. 4. COD removal and methanization efficiencies for test $4(8.91 \mathrm{~g}$ $\mathrm{COD} / \mathrm{L})$.

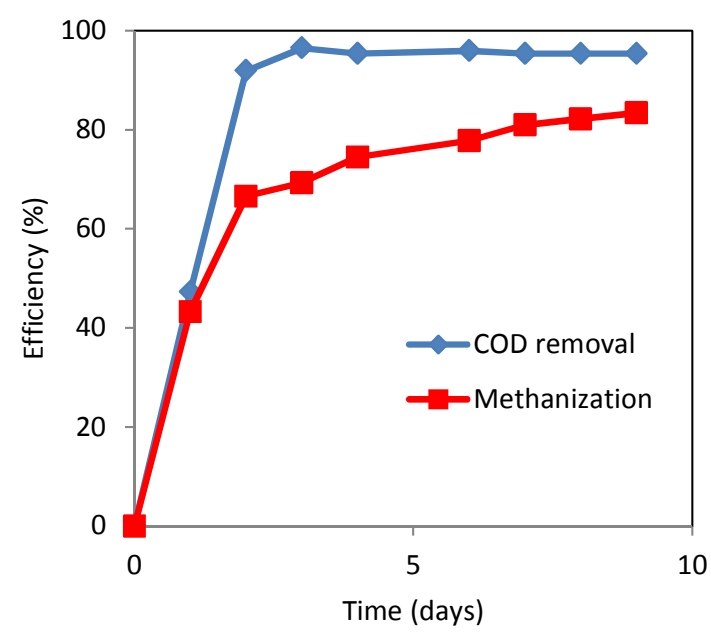

Fig. 5. COD removal and methanization efficiencies for test $5(17.27 \mathrm{~g}$ $\mathrm{COD} / \mathrm{L})$.

The evolution of the CODpf removal as a function of the applied load (Fig. 6) shows that in the first and second days the COD removal is very similar with exception of the higher load. The additional COD removal in the second day is very small in comparison with what was observed in the first day. For the higher load by comparing the percentage removal attained in the first and the second days it is possible to see that not all the substrate is removed in the first day.

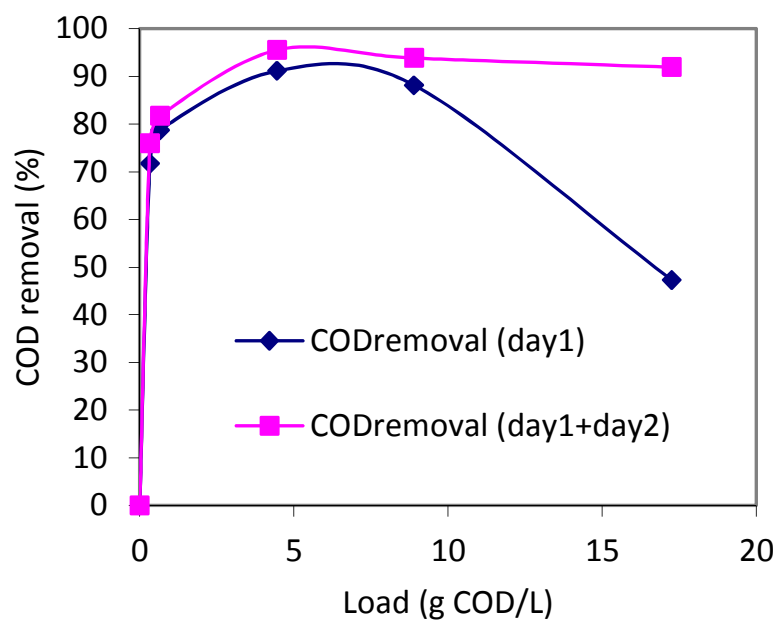

Fig. 6. Evolution of COD removal with applied load..

A linear relation was found between the applied load and the volumetric methane production obtained in the first day (Fig. 7) except for the higher load were a decrease in the relation $\mathrm{CH}_{4} /$ load was observed. This discrepancy is due to the fact that not all the organic matter is available for the microorganisms to degrade since it is adsorbed onto the biomass particles, causing a lower methane production than would be expected from the observed COD removal. These results confirm the rapid adsorption of organic substrate onto the biological sludge reported by Hwu [10] and by Nadais et 
al. [11]. Yet when correlating the total volume of $\mathrm{CH}_{4}$ produced in the first and second days with the applied loads a linear correlation is observed. Fig. 8 presents the values of methanization percentage of the removed CODpf attained in the first and in the second days of the tests as functions of the applied loads. The differences observed in the methanization of the removed substrate between the first and the second days indicate that a part of the COD removed during the first day is methanized only in the second day. This result is in accordance of the proposed duration of two days for the feedless period of intermittent operation of UASB reactors treating dairy wastewater [1].

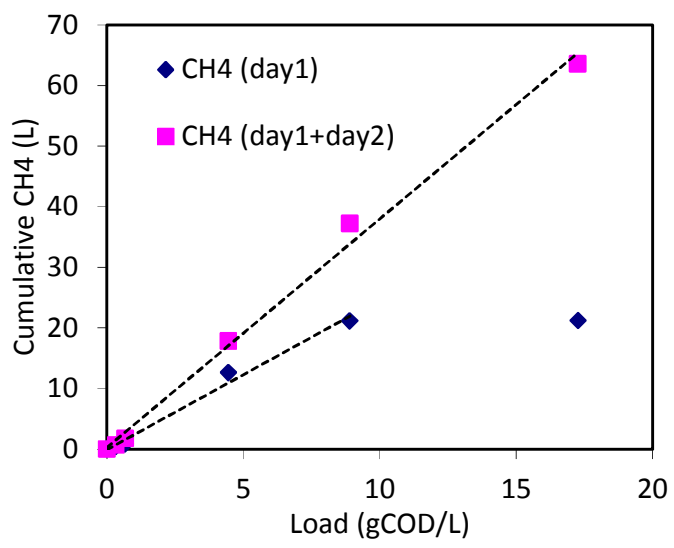

Fig. 7. Correlation between applied load and methane production .

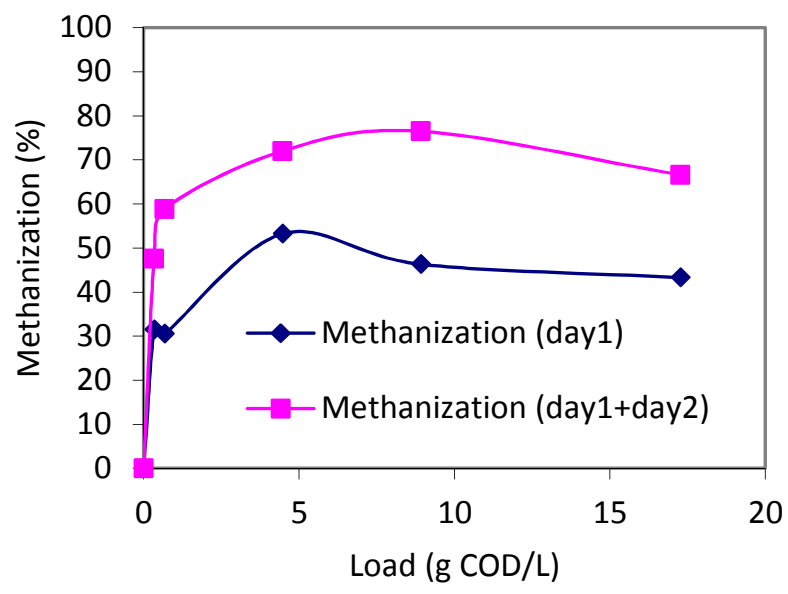

Fig. 8. Evolution of methane production with applied load.

The methane content in the produced biogas varied from $50 \%$ to $90 \%$ for all the tests being higher by the end of each test. The soluble COD fraction (CODmf) is the fraction available for microorganism metabolism and is around $20 \%$ to $40 \%$ of the CODpf (colloidal + soluble COD) in the beginning of tests (see Figs. 2 and 3). In all the tests the average $\mathrm{pH}$ values varied between 7 and 8 the lowest value reached being 6.5 . The VFA concentrations determined in all the tests never surpassed $2 \mathrm{mg} \mathrm{HAc/L}$, always being under the threshold toxicity limit of $3 \mathrm{~g} \mathrm{HAc/L}$ suggested by Malina and Pohland [12]. As an example Fig. 9 presents the VFA profile for test 4 (load of $8.91 \mathrm{~g} \mathrm{COD} / \mathrm{L}$ ), where it can be seen that a significant percentage of the produced VFA is butyric acid, an intermediate substrate related to the degradation of fatty matter and LCFA in anaerobic systems [13].

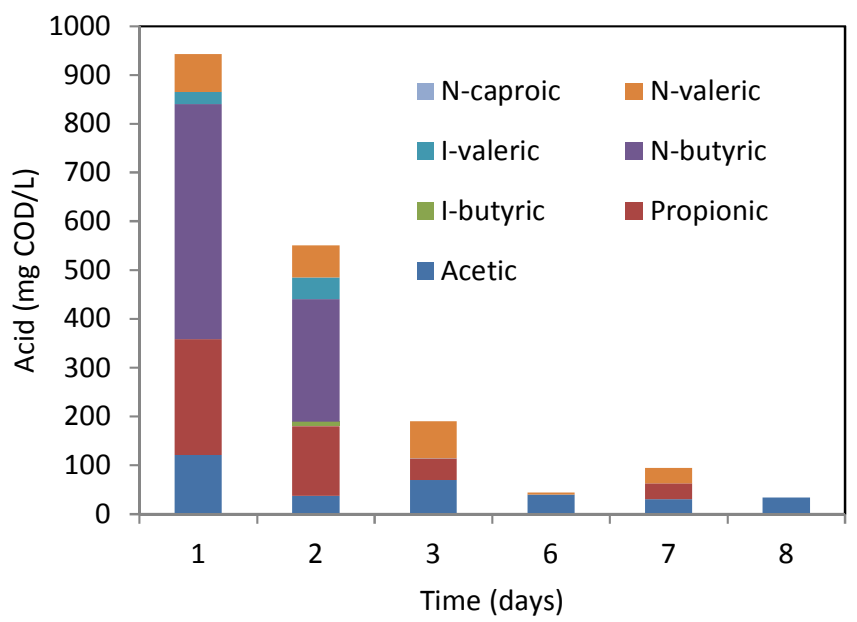

Fig. 9. VFA profile for test 4 .

The specific CODcolloidal+soluble removal rates (qCODpf) and the specific methane production rates $\left(\mathrm{qCH}_{4}\right)$ were obtained by the initial velocity method $(\Delta t=1$ day) and were adjusted to the Monod model (1) and to the uncompetitive inhibition model or Haldane model (2), both described in [14]. The least squares method was applied and commercial software, Scientist (C) version 2.0 1994, was used, with an integration method based on the Powell algorithm and initial values search by the double simplex method. The quality of the fitting was assessed by the coefficient of determination $r^{2}$, see Fig. 10 and Table III.

$$
\begin{gathered}
\mathrm{q}=\frac{\mathrm{q}_{\max }}{K_{s}+S} \\
\mathrm{q}=\frac{\mathrm{q}_{\max }}{1+\frac{\mathrm{K}_{\mathrm{s}}}{\mathrm{S}}+\frac{\mathrm{S}}{\mathrm{K}_{\mathrm{i}}}}
\end{gathered}
$$

where: $\mathrm{q}$ is the specific substrate removal rate $(\mathrm{g} \mathrm{COD} / \mathrm{g}$ VSS.d); $\mathrm{q}_{\max }$ is the maximum substrate specific removal rate (g COD/g VSS.d); $\mathrm{K}_{\mathrm{s}}$ is the half-velocity constant $(\mathrm{g} / \mathrm{L}), \mathrm{K}_{\mathrm{i}}$ is the Haldane inhibition constant $(\mathrm{g} / \mathrm{L})$ and $\mathrm{S}$ is the substrate concentration $(\mathrm{g} / \mathrm{L})$.

According to the values of $r^{2}$ the model that provided a better fit of the experimental data was the Monod model. The specific rate of methane production $\left(\mathrm{qCH}_{4}\right)$ is approximately $45 \%$ of the specific CODpf removal rate (see Fig. 11) which is 
justified by the fact that this rates were calculated using the initial velocity method $(\Delta t=1$ day $)$ and there is a lag between initial COD removal and methane production.

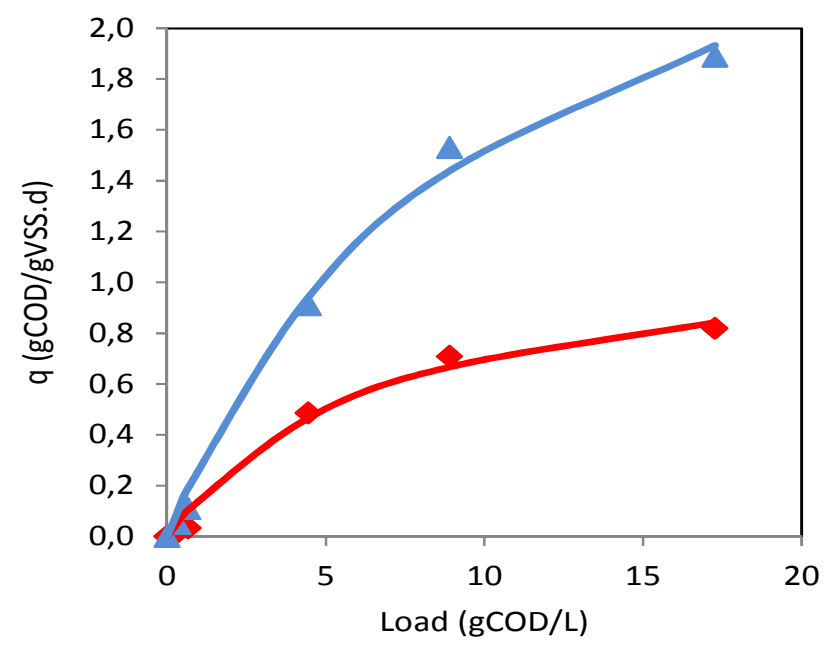

qCH4 (experimental)

$\Delta$ qCODpf (experimental)

qCH4-Monod

qCODpf-Monod

Fig. 10. Fitting of experimental data to the Monod model.

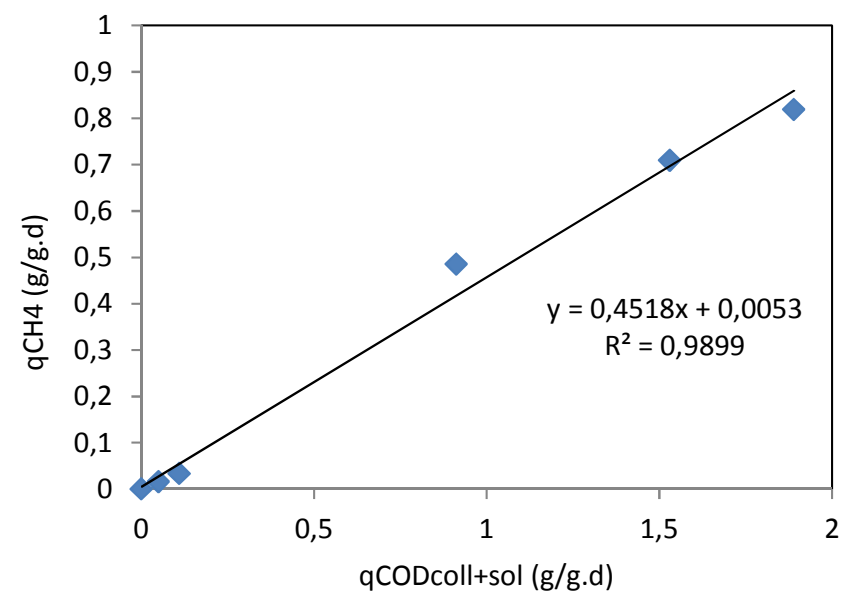

Fig. 11. Relation between specific COD removal rate and specific methane production rate..

TABLE III. KINETIC PARAMETRES

\begin{tabular}{|c|c|c|c|}
\hline Parameter & $\mathrm{CODpf}^{1)}$ & $\mathrm{CH}_{4}{ }^{1)}$ & CODpf $^{2)}$ \\
\hline $\mathrm{q}_{\max }$ & 3.044 & 1.1750 & 2.4 \\
$\mathrm{~K}_{\mathrm{s}}$ & 9.9323 & 6.7140 & 9.6 \\
$\mathrm{r}^{2}$ & 0.9941 & 0.9866 & 0.9974 \\
\hline
\end{tabular}

1) This work; 2) Reference [15].

Fig. 12 and Table III present a comparison of the specific COD removal rates obtained in this work and those obtained in batch reactors with no recirculation with a biomass content of $5 \mathrm{~g} \mathrm{VSS} / \mathrm{L}$ [15]. It can be seen that for loads above $5 \mathrm{~g}$ $\mathrm{COD} / \mathrm{L}$ recirculation improves the COD removal rate in about $30 \%$ for tests performed with the same VSS content compared to the results with no recirculation. This means that the recirculation of the treated effluent and the hydrodynamic conditions have a significant beneficial influence upon the kinetics of the degradation process in discontinuous anaerobic systems.

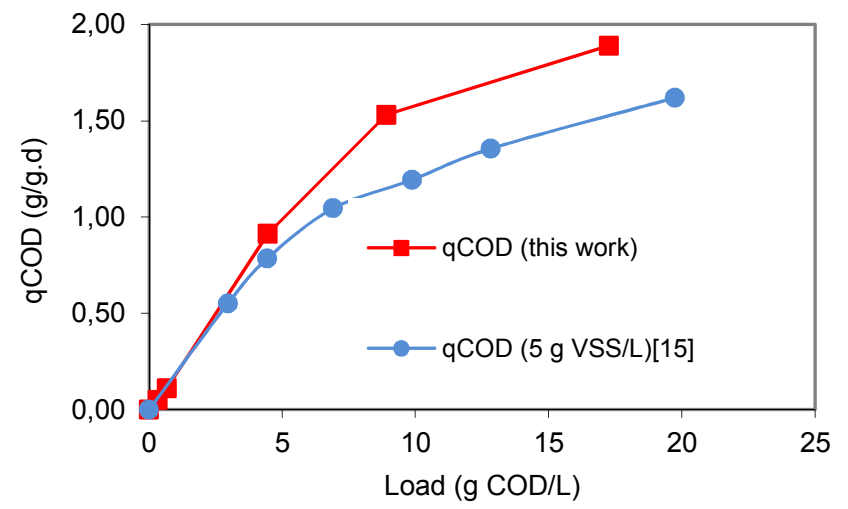

Fig. 12. Comparison of data from this work and from literature [15].

Figs. 13 and 14 present the COD balances for tests 4 (organic load of $8.91 \mathrm{~g} \mathrm{COD} / \mathrm{L}$ ) and for a test performed in similar conditions but with no effluent recirculation performed with an organic load of $9 \mathrm{~g} \mathrm{COD} / \mathrm{L}$ and $5 \mathrm{~g} \mathrm{VSS} / \mathrm{L}$, [1]. Surprisingly it can be seen that methane production is more rapid in the test with no recirculation. Yet initial adsorption (retained COD) is more pronounced in the test with effluent recirculation probably due to a more complete contact between the substrate and the biomass. Although initial adsorption is higher with effluent recirculation also the substrate degradation is higher for this condition leading to higher methanization efficiency.

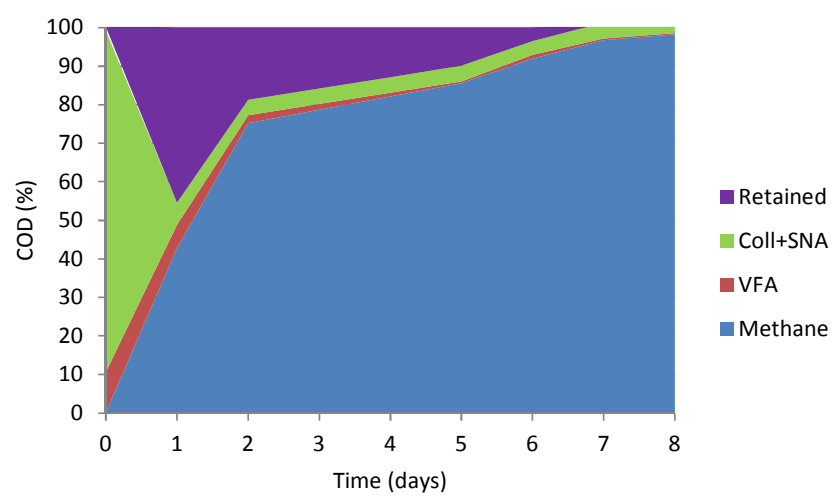

Fig. 13. COD balance for test $4(8.91 \mathrm{~g} \mathrm{COD} / \mathrm{L})$; coll $=$ colloidal, $\mathrm{SNA}=$ soluble not acidified. 


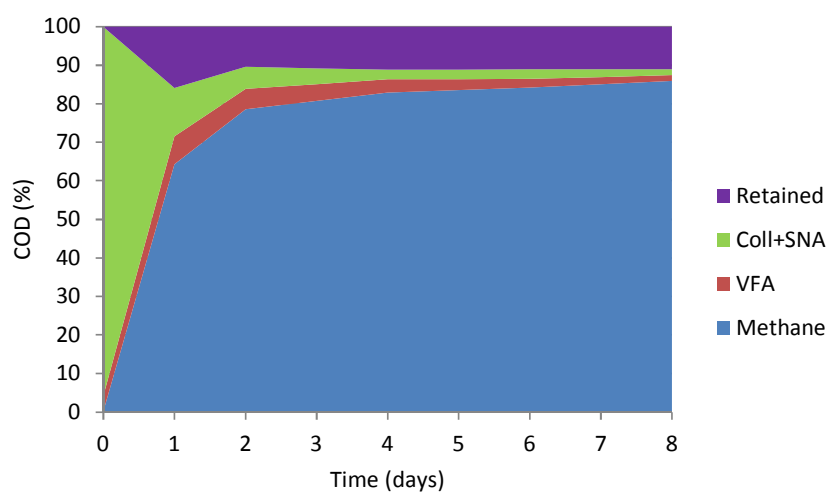

Fig. 14. COD balance for a batch test without recirculation with a load of $9 \mathrm{~g}$ $\mathrm{COD} / \mathrm{L}$ and $5 \mathrm{~g} \mathrm{VSS} / \mathrm{L}$ (adapted from [15]); coll = colloidal, SNA = soluble not acidified.

These results are in agreement with what was reported by Nadais et al. [8], that observed an improvement of intermittent UASB reactor performance when effluent recirculation was applied during the feedless periods. (methanization raised to $95 \%$ as compared to $80-88 \%$ attained with no effluent recirculation).

The results obtained in this work also suggest that for organic loads above $10 \mathrm{~g}$ COD/L the feedless periods of intermittent operation should be longer than the feed periods as has been suggested by Coelho et al. [2]. On the other hand it was observed that the monitoring of high rate reactors treating complex fat containing wastewater based on the COD of the produced effluent may be misleading in what concerns the real biological degradation $[16,17]$.

\section{CONCLUSIONS}

In laboratory experiments of UASB reactors with total effluent recirculation treating dairy wastewater there is a rapid COD removal in the first day of the tests, evidenced by the decrease in CODcolloidal+soluble, which removal is not followed by a biological degradation evidenced by $\mathrm{CH}_{4}$ production. This is due to adsorption of the organic matter onto the surface of the biological sludge since adsorption is faster than biological degradation. The $\mathrm{CH}_{4}$ specific production rate, calculated by the initial velocity method $(\Delta \mathrm{t}=1$ day) was about $45 \%$ of the specific CODcolloidal+soluble removal rate. This confirms that the monitoring of high rate reactors based on the COD of the liquid phase may be misleading $[16,17]$. The discrepancy between the initial COD removal and the $\mathrm{CH}_{4}$ production was observed mostly in the first day of the tests fading on the second day which suggests that a period for intermittency in UASB reactors should be higher than one day and possible two days.

In what concerns the influence of the hydrodynamic conditions upon the behavior of high rate reactors treating milk wastewaters it can be said that effluent recirculation during feedless periods improved significantly (up to $30 \%$ ) the specific CODcolloidal+soluble removal rate in comparison to what was observed in classical batch reactors with no recirculation. A more complete substrate degradation was also observed with effluent recirculation.

\section{ACKNOWLEDGMENT}

This work was performed with funding from FCT-Fundação para a Ciência e Tecnologia, Portugal (PTDC/AMB/65025/2006).

\section{REFERENCES}

[1] H. Nadais, I. Capela, L. Arroja, A. Duarte, "Optimum cycle time for intermittent UASB reactors treating dairy wastewater", Water Research, vol. 39 , no. 8, pp. 1511-1518, 2005.

[2] N. Coelho, A. Rodrigues, L. Arroja, I. Capela, "Effect of non-feeding period length on the intermittent operation of UASB reactors treating dairy effluents". Biotechnology Bioengineering, vol. 96, no 2, pp. 244249, 2007.

[3] M. Viñas, C. Galain, M. Lois, "Treatment of proteic wastewater in continuous and intermittent UASB reactors",. VI International Symposium on Anaerobic Digestion, São Paulo, Brazil, vol. 1, pp. 321327, 1991.

[4] S. Sayed, "Anaerobic treatment of slaughterhouse wastewater using the UASB process", Ph.D Thesis, Agricultural University of Wageningen, Wageningen, The Netherlands, 1987.

[5] S. Sayed, and M. Fergala, "Two-stage UASB concept for treatment of domestic sewage including sludge stabilisation process", Water Science and Technology, vol. 32, no 11, pp. 55-63, 1995.

[6] M.R. Gonçalves, J.C. Costa, I.P. Marques, M.M. Alves, "Strategies for lipids and phenolics degradation in the anaerobic treatment of olive mill wastewater", Water Research, vol. 46, no 6, pp. 1684-1692, 2012.

[7] J. Palatsi, M. Laureni, M.V. Andrés, X. Flotats, H.B. Nielsen, I. Angelidaki, "Recovery strategies from long-chain fatty acids inhibition in anaerobic thermophilic digestion of manure", Bioresource Technology, vol. 100, no 20, pp. 4588-4596, 2009.

[8] H. Nadais, I. Capela, L. Arroja, "Intermittent vs continuous operation of upflow anaerobic sludge bed reactors for dairy wastewater and related microbial changes", Water Sci. Technol., vol. 54, no 2, pp. 103-109, 2006.

[9] M.A. Pereira, O.C. Pires, M, Mota, M.M., Alves, "Anaerobic biodegradation of oleic and palmytic acids: evidence of mass transfer limitations caused by long chain fatty acid accumulation onto the anaerobic sludge". Biotechnol. Bioeng., vol. 92, no 1, 15-23, 2005.

[10] C.S. Hwu, "Enhancing anaerobic treatment of wastewaters containing oleic acid", $\mathrm{PhD}$ thesis, Agricultural University of Wageningen, Wageningen, The Netherlands, 1997.

[11] H. Nadais, I. Capela, L. Arroja, A. Duarte, "Biosorption of milk substrates onto anaerobic flocculent and granular sludge", Biotechnol. Prog., vol. 19, pp. 1053-1055, 2003.

[12] J.E. Malina and F. Pohland, "Design of anaerobic processes for the treatment of industrial and municipal wastes", Technomic Publishing Company, Inc. Lancaster, Pennsylvania, USA, 1992.

[13] G. Silvestre, A. Rodríguez-Abalde, B. Fernández, X. Flotats, A. Bonmatí, "Biomass adaptation over anaerobic co-digestion of sewage sludge and trapped grease waste",Bioresource and Technology, vol. 102, pp. 6830-6836, 2011.

[14] B. Desjardins and P. Lessard, "Modélisation du procédé de digestion anaérobie", Sciences et Techniques de L'eau, vol. 25, no 2, pp. 119-136, 1992.

[15] H. Nadais, I. Capela, L. Arroja, A.. Duarte, "Kinetic analysis of anaerobic degradation of dairy wastewater", Proc. $9^{\text {th }}$ World Congress on Anaerobic Digestion-2001, Antwerp, Belgium, 2-5 September, 203208, 2001.

[16] H. Nadais, "Dairy wastewater treatment with intermittent UASB reactors", Ph.D Thesis, University of Aveiro, Aveiro, Portugal, 2002 (in portuguese).

[17] J. Jeganathan, G. Nakhla, A. Bassi, "Long-term performance of highrate anaerobic reactors for the treatment of oily wastewater", Environ. Sci. Technol., vol. 40, pp. 6466-6472, 2006

\section{Creative Commons Attribution License 4.0 (Attribution 4.0 International, CC BY 4.0)}

This article is published under the terms of the Creative Commons Attribution License 4.0 https://creativecommons.org/licenses/by/4.0/deed.en_US 